\title{
Quantitative studies of the wakes of freely flying birds in a low-turbulence wind tunnel
}

\author{
G. R. Spedding, A. Hedenström, M. Rosén
}

1

Exp Fluids (2003) 34:291-303

In Spedding et al. (2003), the drag calculated from the $x$-momentum equation in Eq. (10) is given in an incorrect intermediate form between two correct alternatives. The incorrect expression for the drag per unit span, $D$ ', was written

$D^{\prime}=\rho U_{0}^{2} \int_{-h / 2}^{h / 2}\left(u(z)-u^{2}(z)\right) d z$

for integrating through a wake profile, $u(z)$ over height $h$. The correct versions are

$D^{\prime}=\rho U_{0}^{2} \int_{-h / 2}^{h / 2}\left(\frac{u(z)}{U_{0}}-\left(\frac{u(z)}{U_{0}}\right)^{2}\right) d z$ or

$D^{\prime}=\rho \int_{-h / 2}^{h / 2}\left(U_{0} u(z)-u^{2}(z)\right) d z$

The calculations in the paper are correct, and do not reflect the typographical error.

\section{Reference}

Spedding GR, Hedenström A, Rosén M (2003) Quantitative studies of the wakes of freely flying birds in a low-turbulence wind tunnel. Exp Fluids 34:291-303

Received: 1 January 2004

Published online: 7 July 2004

(C) Springer-Verlag 2004

The online version of the original article can be found at http:// dx.doi.org/10.1007/s00348-002-0559-8

G. R. Spedding $(\bowtie)$

Department of Aerospace and Mechanical Engineering,

University of Southern California, Los Angeles,

CA 90089-1191, USA

E-mail: geoff@usc.edu

A. Hedenström, M. Rosén

Department of Animal Ecology, Lund University,

Ecology Building, SE-223 62 Lund, Sweden 